\title{
Bone mineral density in hypoparathyoidism: Not a useful tool (a case in point)
}

\author{
Ana VALEA ${ }^{1,2}$, Florica SANDRU ${ }^{3,4}$, Mihai Cristian DUMITRASCU ${ }^{3,5}$, \\ Rene BALOESCU ${ }^{6}$, Mara CARSOTE ${ }^{3,6}$ \\ ${ }^{1}$ Clinical County Hospital, Cluj-Napoca, Romania \\ 2"Iuliu Hatieganu" University of Medicine and Pharmacy, Cluj-Napoca, Romania \\ 3"Carol Davila" University of Medicine and Pharmacy, Bucharest, Romania \\ ${ }^{4}$ Elias Emergency University Hospital, Bucharest, Romania \\ ${ }^{5}$ Emergency University Hospital, Bucharest, Romania \\ 6"C.I. Parhon" National Institute of Endocrinology, Bucharest, Romania
}

\begin{abstract}
Hypoparathyroidism is a rare condition associating autoimmune, genetic, post-operatory (most frequent) or idiopathic causes. Low calcium causes neuromuscular irritability of chronic or acute type like muscle crample, paresthesia, tingling, cardiac rhythm anomalies, seizures, etc. Despite calcium and active vitamin $D$ replacement, acute complications are frequently seen and generally a reduced quality of life is registered since pathogenic medication like parathormone drug substitution is not currently available in daily practice. Other complications are due to overtreatment with calcium and vitamin D like kidney stones and associated urinary infections and hypercalciuria while increased calcium-phosphor product causes calcifilaxia of different locations causing complications like skin necrosis, brain calcifications with seizures, etc. We introduce a case of hypoparathyoidism in association with other co-morbiditis and a brief discussion around the case related to bone mineral density anomalies or usefulness in general panel of investigations in this particular topic. This is a 43-year old non-smoking male coming from non-endemic area that had a small lesion of skin necrosis at left hand. He has autoimmune thyroiditis and on admission low values of calcium and PTH $2 \mathrm{pg} / \mathrm{ml}$ (normal 15-65 pg/ml) are consistent for the diagnosis of hypoparathyroidsm, probably of autoimmune cause. Central DXA shows high BMD at each site. He was offered calcium and vitamin D replacements with a mild clinical improvement. This case of autoimmune hypoparathyroidism associated with Hashimoto's thyroiditis highlights the idea of high DXA-BMD due to cortical and trabecular effects of PTH deficiency.
\end{abstract}

Keywords: skin necrosis, hypoparathyroidism, bone mineral density, thyroid nodule, thyroiditis
Abbreviations
$\mathrm{BMD}=$ bone mineral density
DXA $=$ dual-energy $X$-ray absorptiometry
$\mathrm{PTH}=$ parathormone

$\mathrm{TSH}=$ thyroid stimulating hormone

TBS $=$ trabecular bone score 


\section{INTRODUCTION}

Hypoparathyroidism is a rare condition associating low calcium and parathormone levels of different causes like autoimmune, genetic, post-operatory (most frequent) or idiopathic $(1,2)$. Low calcium causes neuromuscular irritability of chronic or acute type like muscle crample, paresthesia, tingling, cardiac rhythm anomalies, seizures etc. $(1,2)$. Despite calcium and active vitamin D replacement, acute complications are frequently seen and generally a reduced quality of life is registered since pathogenic medication like parathormone drug substitution is not currently available in daily practice (3). Parathormone represents the key player of mineral metabolism and its role is related to adequate synthesis and actions of vitamin $D$, too $(4,5)$. Other complications are due to overtreatment with calcium and vitamin D like kidney stones and associated urinary infections and hypercalciuria while increased calcium-phosphor product causes calcifilaxia of different locations causing complications like skin necrosis, brain calcifications with seizures etc. $(1,2,3)$.

\section{AIM}

We introduce a case of hypoparathyoidism in association with other co- morbiditis and a brief discussion around the case related to bone mineral density anomalies or usefulness in general panel of investigations in this particular topic.

\section{METHOD}

This is a case presentation. The patient agreed for the introduction of his medical records.

\section{CASE DATA}

\section{Admission}

This is a 43-year old non-smoking male coming from non-endemic area that had a small lesion of skin necrosis at left hand (at the level of this $4^{\text {th }}$ finger). After remission he was referred for an endocrine assessment because the patient had a history of autoimmune hypothyroidism. Also he experienced acral paresthesia of different intensities since last several months and a value of low serum calcium has been detected.

\section{Assessments}

On admission the general and endocrine clinical evaluation was not significant. The blood assays were done and revealed a very low value of total calcium of $5.09 \mathrm{mg} / \mathrm{dl}$ (normal levels between 8.5 and $10.2 \mathrm{mg} / \mathrm{dl}$ ) as well as ionic calculated calcium of $2.1 \mathrm{mg} / \mathrm{dl}$ (normal values between 3.9 and $4.9 \mathrm{mg} / \mathrm{dl}$ ); normal total serum proteins of $7.55 \mathrm{mg} / \mathrm{dl}$ (normal limits of 6.5-8.7 mg/dl), high serum phosphorus of $6.2 \mathrm{mg} / \mathrm{dl}$ (normal between 2.5 and $4.5 \mathrm{mg} / \mathrm{dl}$ ). In addition to these aspects the subject had normal renal and hepatic function, hemoglobin, serum magnesium $(1.5 \mathrm{mg} / \mathrm{dl}$, normal between 1.6 and $2.4 \mathrm{mg} / \mathrm{dl})$. 25-hidroxivitamin D was of $38 \mathrm{ng} / \mathrm{ml}$ (normal level is more than

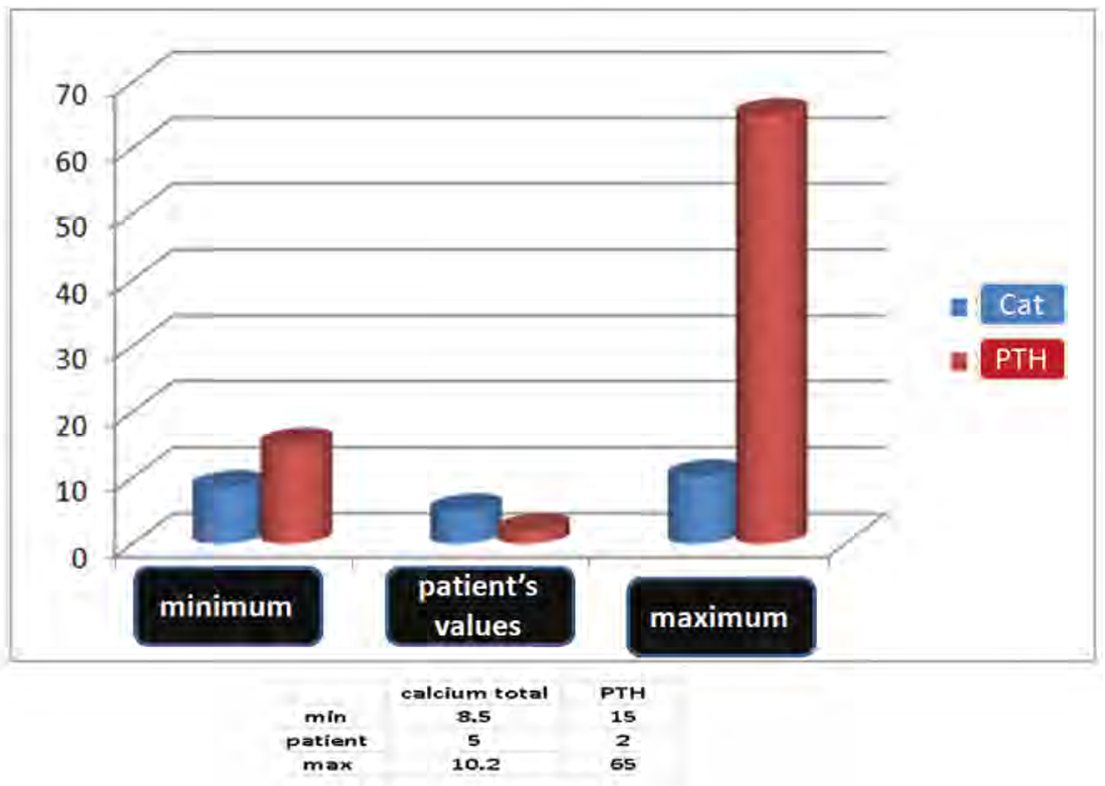

FIGURE 1. Total serum calcium and PTH levels on a 43-year old patient with hypoparathyroidism; normal levels are displayed within the chart 
$30 \mathrm{ng} / \mathrm{ml}$ ) and PTH (parathormone) was of $2.15 \mathrm{pg} /$ $\mathrm{ml}$ (normal between 15 and $65 \mathrm{pg} / \mathrm{ml}$ ) (Figure 1).

The values of PTH remained low when the assays were repeated. The blood bone turnover markers showed CrossLaps (marker of bone resorption) of $0.23 \mathrm{ng} / \mathrm{ml}$ (normal between 0.158 and $0.442 \mathrm{ng} / \mathrm{ml}$ ), and osteocalcin, respective total alkaline phospatase (markers of bone formation) of $8.25 \mathrm{ng} / \mathrm{ml}$ (normal ranges between 14 and $42 \mathrm{ng} / \mathrm{ml}$ ), respective $53 \mathrm{U} / \mathrm{l}$ (normal less than $108 \mathrm{U} / \mathrm{I})$. TSH (thyroid stimulating hormone) was of $3 \mu \mathrm{UI} / \mathrm{ml}$ (normal between 0.5 and $4.5 \mu \mathrm{UI} / \mathrm{ml}$ ). Anti-thyroperoxidase antibodies of $417 \mathrm{U} / \mathrm{ml}$ confirmed the diagnosis of Hashimoto's thyroiditis (normal levels less than $35 \mathrm{UI} / \mathrm{ml}$ ) with normal values of anti-thyoroglobulin antibodies of 30-70 UI/ $\mathrm{ml})$.

Thyroid ultrasound pointed out hypoechoic pattern and a thyroid hypo-echogenous nodule of
$8 \mathrm{~mm}$ at left lobe. Anterior cervical intravenous contrast computed tomography revealed no tumor but a small thyroid nodule of 8 by $5 \mathrm{~mm}$ at the level of left lobe which was homogenous and well shaped. Central DXA (Dual-Energy X-Ray Absorptiometry) showed at L1-4 lumbar level a BMD (bone mineral density) value of $1.485 \mathrm{~g} / \mathrm{sqcm}$, T-score of 2.2 SD, Z-score of 1.6 SD (Figure 2).

$1 / 3$ distal radius DXA at non-dominant forearm revealed a BMD of $0.763 \mathrm{~g} / \mathrm{sqcm}$, T-score of -0.5 SD, Z-score of -0.5 SD (Figure 3). Hip DXA showed femoral neck BMD of $1.328 \mathrm{~g} / \mathrm{sqcm}$, T-score of 2 $\mathrm{SD}$, Z-score of $1.9 \mathrm{SD}$, total hip BMD of $1.363 \mathrm{~g} /$ sqcm, T-score of 1.8 SD, Z-score of 1.6 SD (Figure 4).

\section{Follow-up}

The patient was offered oral calcium of 1-1.5 g per day in addition to calcitriol 0.5-0.75 $\mu \mathrm{g}$ per day (in case the drug was not available he switched to
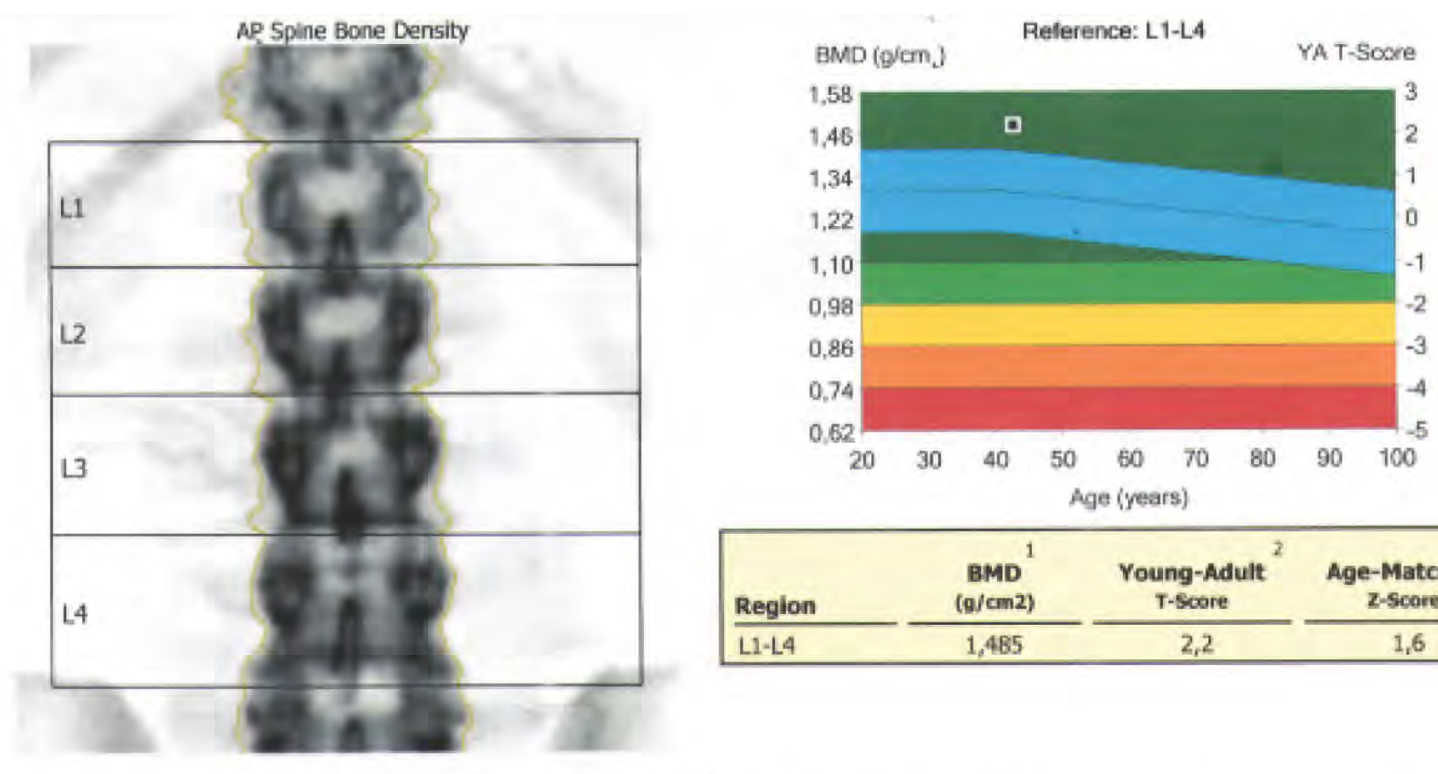

\begin{tabular}{|c|c|c|c|}
\hline Region & BMD $_{(a / c m 2)}^{1}$ & $\begin{array}{c}\text { Young-Adult } \\
\text { T-Score }\end{array}$ & $\begin{array}{c}\text { Age-Matched } \\
\text { Z-Score }\end{array}$ \\
\hline L1-L4 & 1,485 & 2,2 & 1,6 \\
\hline
\end{tabular}

\begin{tabular}{|c|c|c|c|c|c|c|c|c|c|}
\hline Region & $\underset{(\mathrm{g} / \mathrm{cm} 2)}{\mathrm{BMD}}$ & $\begin{array}{l}\text { Young } \\
(\%)\end{array}$ & $\begin{array}{l}\text { T-Adult } \\
\text { T-Score }\end{array}$ & $\begin{array}{l}\text { Age- } \\
(\%)\end{array}$ & $\begin{array}{l}\text { latched } \\
\text { Z-Score }\end{array}$ & $\begin{array}{c}\text { BMC } \\
\text { (g) }\end{array}$ & $\begin{array}{l}\text { Area } \\
(\mathrm{cm} 2)\end{array}$ & $\begin{array}{l}\text { Width } \\
\text { (cm) }\end{array}$ & $\begin{array}{l}\text { Height } \\
\text { (cm) }\end{array}$ \\
\hline L1 & 1,202 & 104 & 0,3 & 97 & $-0,3$ & 19,15 & 15,94 & 4,7 & 3,36 \\
\hline L2 & 1,476 & 119 & 2,0 & 112 & 1,4 & 24,16 & 16,37 & 4,7 & 3,47 \\
\hline L3 & 1,614 & 130 & 3,1 & 123 & 2,5 & 29,30 & 18,15 & 4,8 & 3,78 \\
\hline L4 & 1,594 & 129 & 3,0 & 121 & 2,3 & 33,85 & 21,24 & 5,2 & 4,10 \\
\hline L1-L2 & 1,341 & 112 & 1,2 & 105 & 0,6 & 43,31 & 32,31 & 4,7 & 6,83 \\
\hline L1-L3 & 1,439 & 119 & 1,9 & 112 & 1,3 & 72,61 & 50,46 & 4,8 & 10,61 \\
\hline L1-L4 & 1,485 & 122 & 2,2 & 115 & 1,6 & 106,46 & 71,69 & 4,9 & 14,70 \\
\hline$L 2-L 3$ & 1,549 & 125 & 2,6 & 118 & 2,0 & 53,46 & 34,52 & 4,8 & 7,25 \\
\hline L2-L4 & 1,566 & 126 & 2,7 & 119 & 2,1 & 87,31 & 55,76 & 4,9 & 11,34 \\
\hline L3-L4 & 1,603 & 129 & 3,0 & 122 & 2,4 & 63,15 & 39,38 & 5,0 & 7,88 \\
\hline
\end{tabular}

FIGURE 2. Central lumbar L1-4 DXA on a 43-year old male with autoimmune hypoparathyroidism. High BMD is suggestive for the condition 


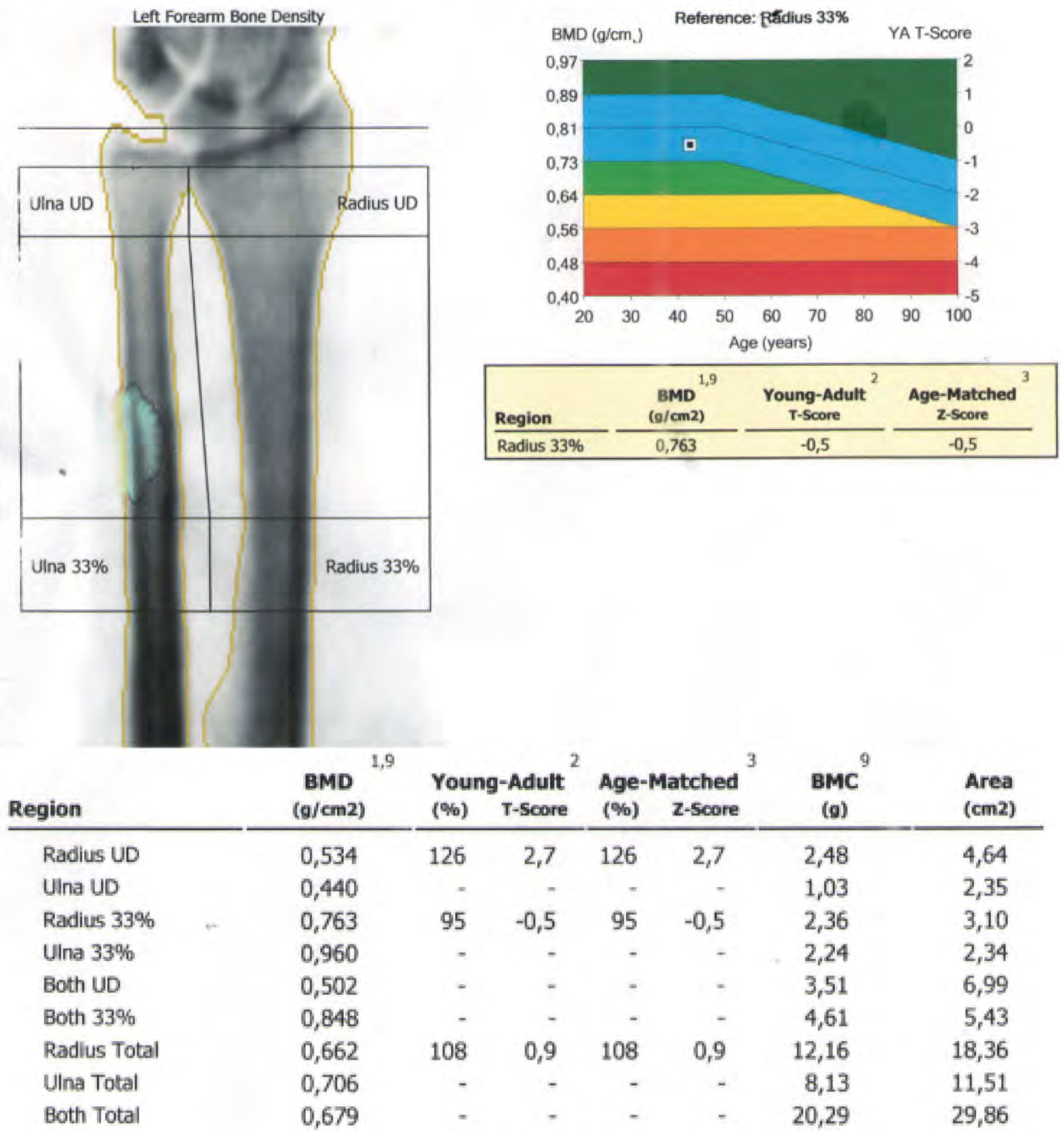

FIGURE 3. Central $1 / 3$ distal radius on a 43-year old male with autoimmune hypoparathyroidism

$1 \mu \mathrm{g}$ alphacalcidol). He was followed for 3 more years and the values of calcium mildly increased with $1 \mathrm{mg} / \mathrm{dL}$ while the PTH levels remained extremely low. The thyroid substitution with $100 \mu \mathrm{g}$ of daily levothyroxine was continued.

\section{DISCUSSION}

Several aspects worth to be discussed related to the present case.

\section{The etiology of primary hypothyroidism}

This is probably an autoimmune case of hypoparathyroidism based on the co-presence of au- toimmune chronic thyroiditis. The HLA connection is most probably involved in this adult onset type while the condition is typically a part of type 1 autoimmune polyglandular syndrome with childhood onset also associating primary chronic adrenal insufficiency and candidosis, type 1 diabetes mellitus and potentially other autoimmune disease because of the AIRE gene mutations (6).

\section{Thyroid involvement and connections}

In this case the patient had Hashimoto's thyroiditis with adequately treated hypothyroidism and a small thyroid nodule which had no clinical relevance despite the fact that parathyroid glands 

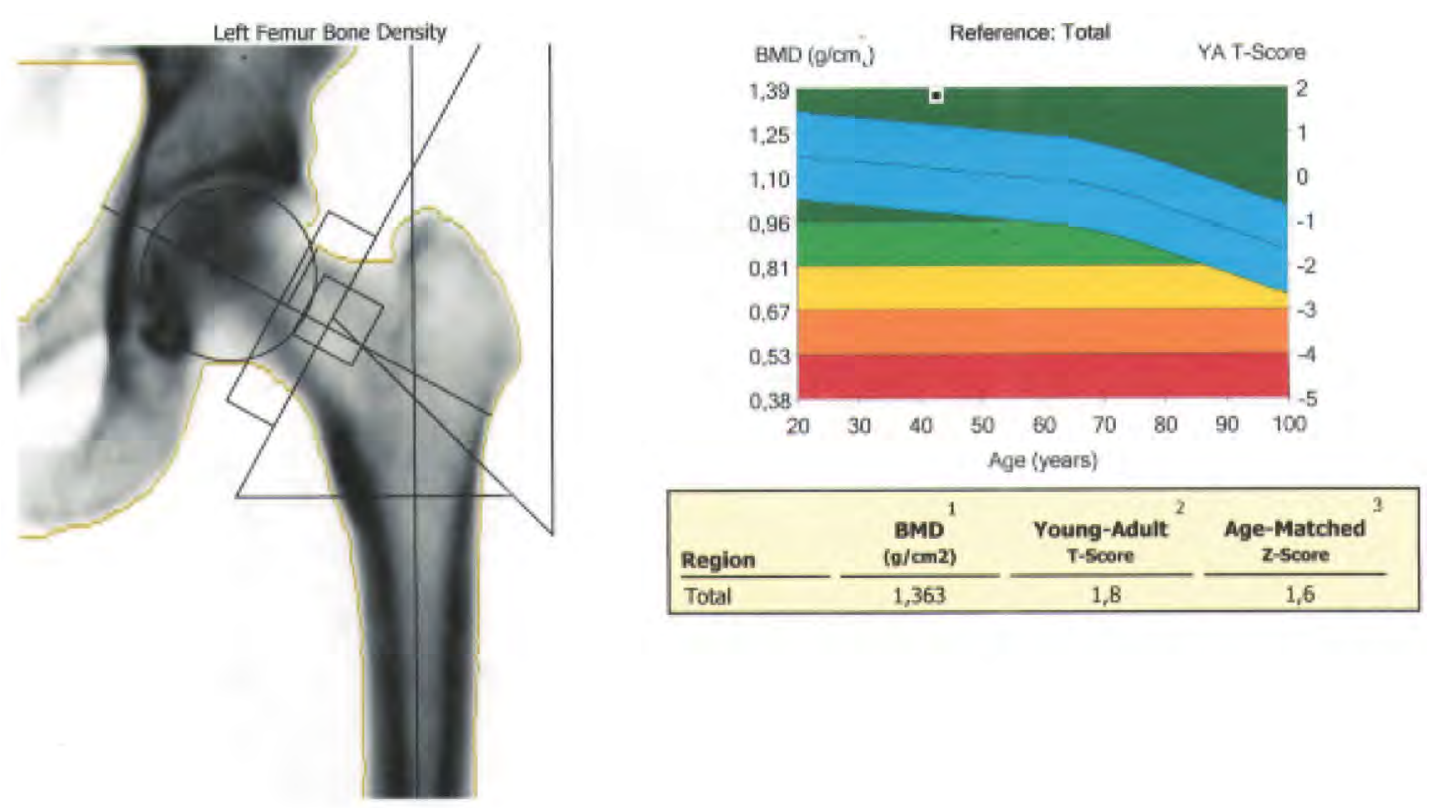

HAL char negults unaralable

\begin{tabular}{|c|c|c|c|c|c|c|c|c|}
\hline \multicolumn{2}{|l|}{ Region } & $\underset{(\mathrm{g} / \mathrm{cm} 2)}{{ }^{1}}$ & \multicolumn{2}{|c|}{ Young-Adult $^{2}$} & \multicolumn{2}{|c|}{ Age-Matched ${ }^{3}$} & $\begin{array}{c}\text { BMC } \\
\text { (g) }\end{array}$ & $\begin{array}{l}\text { Area } \\
(\mathrm{cm} 2)\end{array}$ \\
\hline Neck & & 1,328 & 124 & 2,0 & 123 & 1,9 & 7,46 & 5,62 \\
\hline Upper Neck & & 1,175 & 129 & 2,0 & 128 & 2,0 & 3,24 & 2,76 \\
\hline Lower Neck & + & 1,475 & - & - & - & - & 4,22 & 2,86 \\
\hline Wards & & 1,089 & 113 & 1,0 & 116 & 1,1 & 3,82 & 3,50 \\
\hline Troch & & 1,116 & 120 & 1,7 & 115 & 1,3 & 22,71 & 20,36 \\
\hline Shaft & & 1,717 & - & - & - & - & 25,36 & 14,76 \\
\hline Total & & 1,363 & 124 & 1,8 & 121 & 1,6 & 55,53 & 40,74 \\
\hline
\end{tabular}

FIGURE 4. Central hip DXA on a 43-year old male with autoimmune hypoparathyroidism

damages are positive based on a functional assessment (7). The risk of a malignancy like thyroid cancer is such a nodule is low and the mentioned co-morbidities are not correlated with the risk $(8,9,10)$. The risk of thyroid metastasiss is also low unless disseminated disease is positive (11). We perform a computed tomography of neck because of potential risk of infiltrative disorders (malignant or not) in order to induce the parathyroid glands suppression $(12,13)$. latrogenic hypoparathyroidism is described in type 2 multiple endocrine neoplasia in association with other neuroendocrine neoplasia and endocrine tumors $(14,15)$.

The patient had autoimmune chronic disorder which is more frequent in females but generally an increased prevalence is reported (16). The thyroid dysfunction is typically of hypothyroidism type but thyrotoxicosis has been reported $(16,17)$.

\section{BMD and PTH}

PTH is situated on the mainstream of bone mass control and anomalies of PTH are directly re- flected on BMD on patients with normal renal function or chonic renal insufficiency $(18,19)$. A baseline evaluation of PTH is useful to appreciate the risk of primary or secondary hyperparathyroidism with DXA consequences $(20,21)$. PTH has antagonist effects on skeleton of either anabolic or catabolic type (18). This is modulated based on time exposure (18). If PTH is low, the cortical and trabecular bone mass are high, thus DXA-BMD is increased as seen in this case, with the highest scores at lumbar spine $(18,19)$. A TBS (trabecular bone score) evaluation was not available at that time for the patient. New data suggested, however, that TBS is normal in this condition (19). The complete panel of consequences involving low PTH at bone micro-architecture is still unclear, inclusive the risk of vertebral fractures (18). Other assessments like peripheral quantitative computed tomography at the level of radius showed that cortical is increased (19). Also, cortical volumetric BMD reveals reduced cortical porosity (19). It is still a matter of debate if the bone strength is af- 
fected by trabecular changes (19). Therapy with human recombinant PTH improves bone remodeling with different responses of $\operatorname{BMD}(22,23)$. The therapy with PTH is not lifelong but it may be associated with an improvement of bone resistance to fractures, as well (most probably a transitory effect) $(22,23)$.

\section{CONCLUSION}

This case of autoimmune hypoparathyroidism associated with Hashimoto's thyroiditis highlights the idea of high DXA-BMD due to cortical and trabecular effects of PTH deficiency.

Conflict of interest: none declared Financial support: none declared

\section{REFERENCES}

1. Mannstadt M, Bilezikian JP, Thakker RV, Hannan FM, Clarke BL, Rejnmark L, Mitchell DM, Vokes TJ, Winer KK, Shoback DM. Hypoparathyroidism. Nat Rev Dis Primers. 2017 Aug 31;3:17055.

2. Clarke BL, Brown EM, Collins MT, Jüppner $\mathrm{H}$, Lakatos P, Levine MA, Mannstadt MM, Bilezikian JP, Romanischen AF, Thakker RV. Epidemiology and Diagnosis of Hypoparathyroidism. J Clin Endocrinol Metab. 2016;101(6):2284-99.

3. Hakami Y, Khan A. Hypoparathyroidism. Front Horm Res. 2019;51:109-126.

4. Radu L, Carsote M, GheorghisanGalateanu AA, Preda SA, Calborean V, Stanescu R, Gheorman V, Albulescu DM. Blood Parathyrin and Mineral Metabolism Dynamics. A clinical analyze. Rev.Chim. (Bucharest). 2018;69(10):2754-2758.

5. Cusano NE, Bilezikian JP. Update on hypoparathyroidism. Curr Opin Rheumatol. 2019 Jul; 31(4):381-387.

6. Cianferotti L, Marcucci G, Brandi ML. Causes and pathophysiology of hypoparathyroidism. Best Pract Res Clin Endocrinol Metab. 2018; 32(6):909-925.

7. Dumitru N, Ghemigian A, Carsote M, Albu SE, Terzea D, Valea A. Thyroid nodules after initial evaluation by primary health care practitioners: An ultrasound pictorial essay. Archives of the Balkan Medical Union. 2016; 51(3):434-438.

8. Poiana C, Virtej I, Carsote M, Banceanu M, Sajin M, Stanescu B, loachim D, Hortopan D, Coculescu M. Virilising Sertoli-Leydig cell tumour associated with thyroid papillary carcinoma: Case report and general considerations. Gynecol Endocrinol 2010; 26(8):617-622.

9. Singh Ospina N, Iñiguez-Ariza NM, Castro MR. Thyroid nodules: Diagnostic evaluation based on thyroid cancer risk assessment. BMJ. 2020 Jan 7;368:16670.

10. Carsote M, Albu SE, lorgulescu R, Dumitrascu A, Terzea D, Goldstein A, Poiana C. From vasomotor symptoms to solid and insular papillary thyroid cancer with oxyphil variant areas. Journal of Surgical Sciences. 2015;2(2):87-91.

11. Poiana C, Carsote M, Ardeleanu C, Terzea D, Avramescu ET, Neamtu MC, Miulescu $\mathrm{RD}$. The value of the immunohistochemistry in a case of gastric neuroendocrine tumor and thyroid metastasis. Rom J Morphol Embryol. 2011; 52(1):187-92.

12. Poiana C, Neamţu MC, Avramescu ET, Carsote M, Trifănescu R, Terzea D, Neamtu OM, Ferechide D, Danciulescu Miulescu R. The poor prognosis factors in $\mathrm{G} 2$ neuroendocrine tumor. Rom J Morphol Embryol. 2013; 54(3 Suppl):717-20.

13. Poiana C, Neamţu MC, Avramescu ET, Carsote M, Trifănescu R, Terzea D, Neamtu OM, Ferechide D, Danciulescu Miulescu R. The poor prognosis factors in $\mathrm{G} 2$ neuroendocrine tumor. Rom J Morphol Embryol. 2013; 54(3 Suppl):717-20.

14. Cianferotti L. Classification of Hypoparathyroid Disorders. Front Horm Res. 2019;51:127-138.

15. Poiana C, Neamtu MC, Avramescu ET, Carsote M, Trifanescu R, Terzea D, Neamtu OM, Danciulescu Miulescu R. The dedifferentiation of neuroendocrine tumor metastases: Myth or reality? Rom J Morphol Embryol. 2013; 54(1):201-3.

16. Herath M, Parameswaran V, Thompson M, Williams M, Burgess J. Paediatric and young adult manifestations and outcomes of multiple endocrine neoplasia type 1. Clin Endocrinol (Oxf). 2019 Nov;91(5):633-638.

17. Pyzik A, Grywalska E, MatyjaszekMatuszek B, Roliński J. Immune disorders in Hashimoto's thyroiditis: What do we know so far? J Immunol Res. 2015; 2015:979167.

18. Trifanescu R, Danciulescu Miulescu R, Carsote M, Poiana C. Hypokalemic periodic paralysis as first sign of thyrotoxicosis. J Med Life 2013; 15:6(1):72-75.

19. Formenti AM, Tecilazich F, Giubbini R, Giustina A. Risk of vertebral fractures in hypoparathyroidism. Rev Endocr Metab Disord. 2019 Sep; 20(3):295-302.

20. Silva BC, Rubin MR, Cusano NE, Bilezikian JP. Bone imaging in hypoparathyroidism. Osteoporos Int. 2017 Feb;28(2):463-471.

21. Poiana C, V.Radoi, Carsote M, Bilezekian J. New Clues that May Link Osteoporosis to the Circulating Lipid Profile. Bone Research 2013;1(3):260-266.

22. Poiana C, Carsote M, Radoi V, Mihai A, Capatina C. Prevalent osteoporotic fractures in 622 obese and non-obese menopausal women. Journal of Medicine and Life. 2015;8(4):462-466.

23. Abate EG, Clarke BL. Review of Hypoparathyroidism. Front Endocrinol (Lausanne). 2017 Jan 16;7:172.

24. Marcucci G, Della Pepa G, Brandi ML. Natpara for the treatment of hypoparathyroidism. Expert Opin Biol Ther. 2016 Nov;16(11):1417-1424. 